\title{
Quantitative recommendations for amphibian terrestrial habitat conservation derived from habitat selection behavior
}

\author{
Lukas Indermaur ${ }^{1,2}$ AND Benedikt R. SChmidT ${ }^{3,4,5}$ \\ ${ }^{1}$ Eawag, Swiss Federal Institute of Aquatic Science and Technology, Department of Aquatic Ecology, \\ Überlandstrasse 133, 8600 Dübendorf, Switzerland \\ ${ }^{2}$ WWF Switzerland, Hohlstrasse 110, Postfach, 8010 Zürich, Switzerland \\ ${ }^{3}$ Institut für Evolutionsbiologie und Umweltwissenschaften, Universität Zürich, Winterthurerstrasse 190, 8057 Zürich, Switzerland \\ ${ }^{4}$ KARCH, Passage Maximilien-de-Meuron 6, 2000 Neuchâtel, Switzerland
}

\begin{abstract}
Conservation scientists have noted that conservation managers rarely use scientific information when making decisions. One of the reasons why managers rarely use scientific information may be that conservation scientists rarely provide their knowledge in a way that can directly be used by conservation practitioners. Here we show how quantitative recommendations for conservation can be derived. Previous research on terrestrial habitat selection behavior of toads (Bufo bufo and Bufo viridis) showed that wood deposits are a key resource in the terrestrial habitat. We used habitat-dependence analysis to estimate the amount of this key resource, wood deposits, that individual toads require. Based on these estimates we then quantify the requirements for wood deposits for a population. Additionally, we quantified the area that a population requires. Although wood deposits vary strongly in size, we found little evidence for size preferences: only one species preferred smallest sizes of wood deposits. We report all the estimates in a way that can be directly used by conservation managers. Habitat-dependence analysis is a simple and useful tool to quantify habitat requirements. Provisioning of wood deposits may improve the quality of terrestrial habitat for amphibians. Thereby, managers may increase the carrying capacity of terrestrial habitats and support elevated population densities.
\end{abstract}

Key words: amphibian; behavior; Bufo; habitat dependence; habitat requirement; home range; recommendation; wood deposits.

\section{INTRODUCTION}

Conservation scientists have noted that conservationists and managers rarely use scientific information when making decisions (Sutherland et al. 2004, Pullin and Knight 2005) and it is widely acknowledged that there is a serious gap between conservation science and practice (Arlettaz et al. 2010). One of the reasons why scientific information is underused by conservationists and managers may be that conservation scientists rarely provide their knowledge in a way that can be directly applied to management (Fazey et al. 2005). To become more useful for real-world conservation, conservation science ought to provide recommendations that can be used directly by conservation practitioners (Schmidt 2008a). One example where conservation biologists have provided quantitative recommendations that are directly applicable in conservation practice is the determination of the amount of terrestrial habitat for amphibian populations through the delineation of buffer zones (Semlitsch 1998, Semlitsch and Bodie 2003, Crawford and Semlitsch 2007, Ficetola et al. 2009). Buffer zones

Manuscript received 22 October 2010; revised 18 January 2011; accepted 9 March 2011. Corresponding Editor: T. W. J. Garner.

${ }^{5}$ E-mail: benedikt.schmidt@unine.ch have great appeal because they can be summarized in a single number and are therefore easy to communicate to conservation practitioners and politicians.

Here, we provide a case study showing how practical recommendations can be derived from sound scientific data. Our approach is based on individual behavior and shows how individual behavior and conservation can be linked (Sutherland 1998, Buchholz 2007, Caro 2007, Moore et al. 2008). Habitat-dependence analysis (Kenward 2001) allows us to establish a direct link between habitat selection behavior and conservation. Using habitat-dependence analysis, we quantified the individual and population requirements for a key resource. To do so, we reanalyzed data from a radiotracking study where the goals were to gain a general understanding of variation in individual space use and niche segregation of two sympatric amphibian species (Indermaur et al. 2009a, b).

Our focus is on the behavioral component of habitat selection of amphibians, a highly imperiled group of vertebrates (Stuart et al. 2004). Hitherto, amphibian conservation focused heavily on the aquatic habitat and paid comparatively little attention to the terrestrial habitat (Semlitsch 2003). Yet most species of pondbreeding amphibians spend most time in the terrestrial habitat, suggesting that terrestrial habitat is paramount 


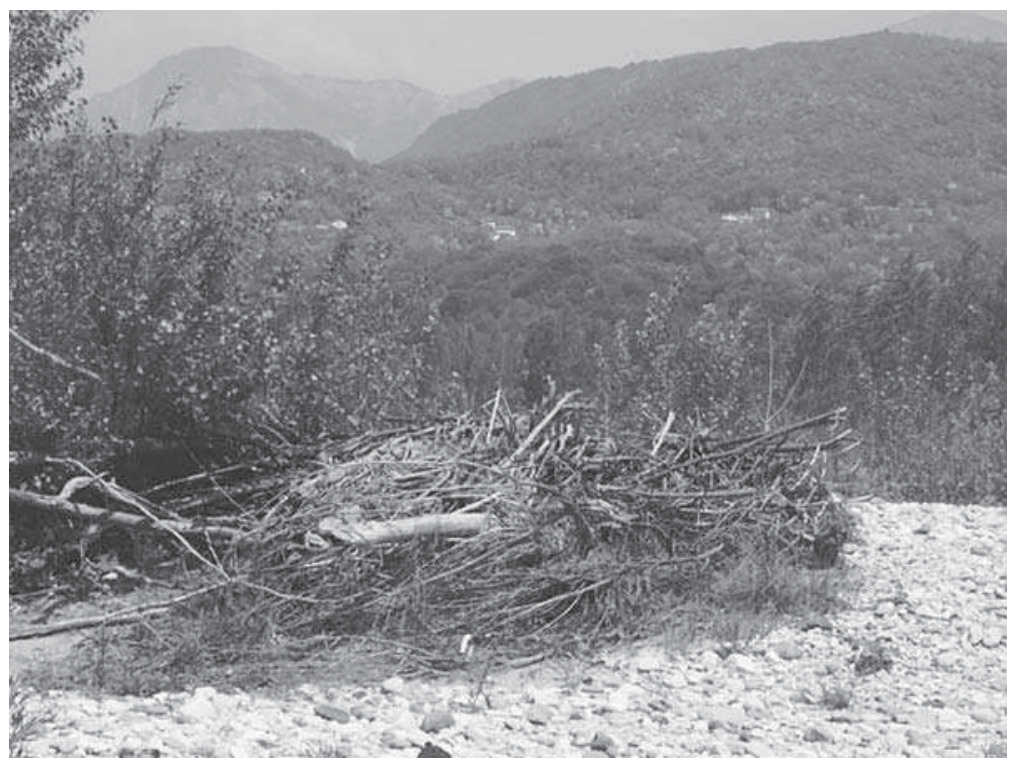

FIG. 1. Photograph of a large wood deposit in the floodplain of the Tagliamento River.

for population viability (Trenham and Shaffer 2005). Moreover, population modeling and analysis of longterm population data suggests that changes in vital rates associated with the terrestrial habitat may have a greater influence on population growth rate than changes in vital rates associated with the aquatic habitat or larval stages (Biek et al. 2002, Schmidt et al. 2005).

We previously showed that wood deposits (hereafter WD; Fig. 1) are a key resource for two sympatric toad species. WD are the most preferred, i.e., they are used over-proportionally compared to their availability (the used:available ratio was 28.6; Indermaur et al. $2009 a, b)$. WD are deposited by the river during floods in open areas (i.e., outside forests) and are composed of large and small pieces of woody debris. WD are usually clearly delimited and are most frequently found in exposed sediments and along the edges of perennial vegetation. They are a multifunctional resource for amphibians because WD provide both shelter and food (Indermaur et al. 2009a, b). For conservation practice, we do not only need to know that WD are a key resource (Indermaur et al. 2009a, b) but we also need to know how much of that resource is necessary. The latter is what we ask here: how much WD does an individual toad or a population need? We used habitat-dependence analysis (Kenward 2001) to quantify the individual requirements for WD. Habitat-dependence analysis allows testing of whether animals adjust home range size to include a constant amount of a habitat or resource within their home ranges (Kenward 2001; Fig. $2)$. For example, if high-quality habitat is scarce and unevenly distributed, animals are thought to increase home range size to meet minimum requirements (MacDonald 1983). Consequently, small home ranges are considered to contain primarily high-quality habitat, compared to large home ranges (Ferguson et al. 1999). These ideas are the conceptual foundation of the habitat-dependence analysis (Kenward 2001). The individual requirements determined by the habitat-dependence analysis allow extrapolation to the population level.

Our goal was to provide quantitative recommendations for terrestrial habitat requirements for amphibians. Keeping in mind that animals require multiple resources, we asked (1) what is the minimum amount of wood deposits that a single individual needs? Because WD occur in different sizes, we asked (2) which size of WD is used over-proportionally compared to availability. Having determined the needs of an individual, we then asked (3) what are the minimum requirements for WD for a population?

\section{Materials and Methods \\ Study species and study area}

We studied two species of toads. Bufo bufo spinosus (European common toad) is a widespread species and typically associated with densely vegetated habitats of late successional stages. Bufo bufo has experienced substantial declines in some parts of its range (e.g., the United Kingdom [Carrier and Beebee 2003] and Switzerland [Schmidt and Zumbach 2005]). Bufo viridis (green toad) is a characteristic species of the hot continental and Mediterranean steppes and prefers early succession habitats (Sindaco et al. 2006). Bufo viridis is listed as a species of community interest in the European Habitats Directive.

Our previous studies on habitat use of toads (Indermaur et al. 2009a, $b$ ) were conducted from midJune through September in 2005 and 2006 on the seventhorder Tagliamento River in northeastern Italy $\left(46^{\circ} \mathrm{N}\right.$, 


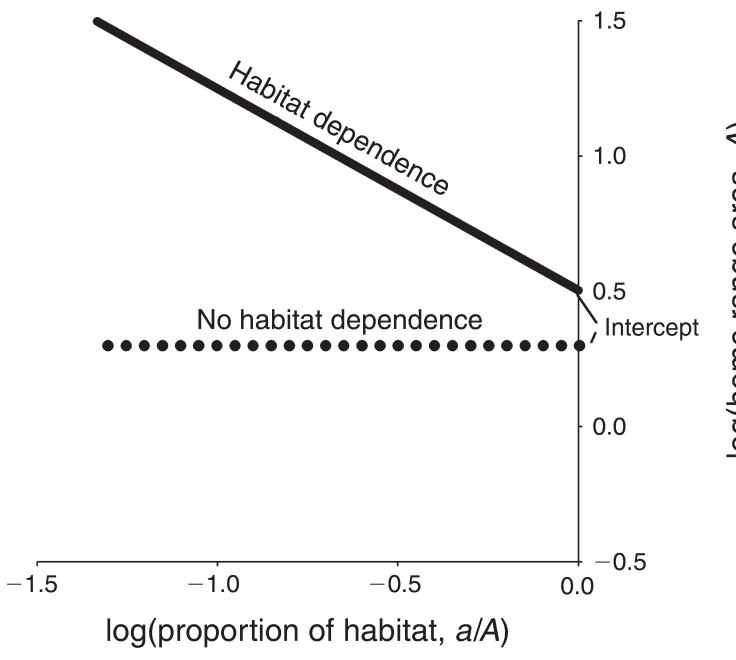

FIG. 2. Habitat-dependence analysis to determine minimum habitat requirements. The log of the area of a habitat type $(a)$ over home range area $(A)$ is regressed on the log of the home range area. The intercept gives the log of the minimum area requirements of $a$. The back-transformed intercept $\left(10^{\log (A)}\right.$ $=10^{0.5}=3.16$ ) for the solid line gives the minimum requirements for $a$, for example, per $\mathrm{m}^{2}$ or ha, depending on the scale used for $a$ and $A$. Regression slopes that are close to -1 indicate that animals increase $A$ to include a minimum area of $a$ within their home ranges, thereby providing evidence for habitat dependence (solid line). When the slope is -1 , all animals include the same area of a habitat type in relation to their home range. The dotted line indicates no habitat dependence as all animals have the same home range size $(A)$, independent of the area of the key habitat $(a)$ included within their home ranges.

$12^{\circ} 30^{\prime} \mathrm{E}$ ). The Tagliamento (catchment area: $2580 \mathrm{~km}^{2}$ ) originates at $1000 \mathrm{~m}$ above se level in the southern European Alps and flows almost unimpeded by dams for $172 \mathrm{~km}$ to the Adriatic Sea. The Tagliamento floodplain is characterized by summer droughts and retains its essentially pristine morphological and hydrological characteristics. The main study area was the active tract (1.1 $\mathrm{km}^{2}$ ) of an island-braided floodplain complex. The study reach contains a spatially complex and temporally dynamic mosaic of water bodies, wood deposits, pioneer vegetation, and vegetated islands embedded into an extensive matrix of exposed riverine sediments (Petts et al. 2000, Indermaur et al. 2009a).

Five mutually exclusive habitat types compose the terrestrial habitat in the floodplain (Indermaur et al. $2009 a)$ : exposed gravel sediments $(67.6 \%$; average values for both years), ponds (13.1\%), established islands (8\%), edge of established islands (6.2\%), dense pioneer vegetation (3.8\%), and area of wood deposits $(1.2 \%$; because WD can be large and heterogeneous, we measure their size in $\mathrm{m}^{2}$, rather than diameter of the wood they are composed of).

\section{Habitat selection}

Home range size (95\% contours) was estimated based on 3079 locations of $56 \mathrm{~B}$. b. spinosus and 2545 locations of 59 B. viridis. On average, we obtained $55 \pm 27.6$ (mean $\pm \mathrm{SD}$ ) locations for each individual of $B . b$. spinosus and $43 \pm 16$ locations of each individual of $B$. viridis. The mean $95 \%$ home range of $B . b$. spinosus and B. viridis were $570 \mathrm{~m}^{2}\left(\mathrm{SD}=872 \mathrm{~m}^{2}\right.$; range, $\left.6-3620 \mathrm{~m}^{2}\right)$ and $2456 \mathrm{~m}^{2}\left(\mathrm{SD}=3946 \mathrm{~m}^{2}\right.$; range, 27-17 $\left.248 \mathrm{~m}^{2}\right)$, respectively. Details on radio-tracking and home range estimation are provided by Indermaur et al. (2009a and appendices therein).

The relative overlap of home ranges among species was $2.67 \% \pm 1.81 \%$ (mean $\pm \mathrm{SD}$ ), and $2.75 \% \pm 1.88 \%$ among individuals of $B$. b. spinosus, and $11.24 \% \pm$ $6.18 \%$ among individuals of $B$. viridis (see Indermaur et al. [2009a] for further details).

\section{Statistical analysis}

Three questions were addressed by three component analyses.

1. What is the amount of wood deposits that a single individual needs?-Habitat-dependence analysis (Kenward 2001) allows to test whether animals adjust home range size to include a minimum amount of a habitat type or resource $(a)$ within their home ranges $(A)$. This can be formalized by regressing the ratio $\log (a / A)$ on $\log (A)$ (Fig. 2). In general, negative slopes suggest that animals increase $A$ to include a minimum amount of $a$ while positive slopes indicate the opposite. However, only slopes that are not significantly different from -1 indicate habitat dependence for the entire population (Fig. 2). If the slope differs from -1 , then individuals do not include a constant minimum area of $a$ in their home ranges. When the home range contains only $a$, then $a=$ $A$. Thus, the back-transformed intercept $\left(10^{\text {intercept }}\right)$ gives the minimum area requirements of $a$ per individual (Kenward 2001). As $a$ is part of $A$, there is always some dependence of $A$ on $a$ or on $a / A$. Therefore, standard null hypothesis tests are invalid. To test whether the slope of the regression of $\log (a / A)$ on $\log (A)$ differed from -1 , we generated 1000 bootstrap samples. For every sample, 100 individuals were randomly selected with replacement. If -1 was included within the $2.5 \%$ and $97.5 \%$ percentiles of the bootstrapped distribution of slopes, then we considered this as evidence for habitat dependence. From the same bootstrap analysis, we also estimated the intercept and confidence limits of both intercept and slope. Statistical analyses were done in $\mathrm{R}$ (R Development Core Team 2009).

2. Which size of wood deposits is used over-proportionally compared to availability? - Suitability and use may change with the area of WD. For conservation purposes it is therefore important to know which size of WD is most preferred by animals. We tested whether the number of used WD of a given size significantly differed from availability using $\chi^{2}$ tests. Used refers to the number of WD containing a radio-tracking location. Available refers to the number of WD within the floodplain (i.e., individual WD, used or available, were the units for the $\chi^{2}$ test). Usage of $\chi^{2}$ tests requires independent observations. The fact that some individu- 
als used the same or multiple WD repeatedly violates this assumption. For testing, we therefore randomly selected one WD per individual from all the WD an individual used. From this sample, the total number of WD across five size classes was calculated. As an individual may have used WD of different sizes, the previous totals may be biased. To minimize bias, we therefore repeated the sampling procedure described above 1000 times and derived mean number (rounded) of used WD per size class.

3. What is the amount of wood deposits that a population needs? - We estimated the minimum area requirements for WD (in $\mathrm{m}^{2} /$ ha) for a population of 100 individuals $\left(a_{\text {pop }}\right.$; a population size of 100 was selected based on the population model of Halley et al. [1996] and recommendations in Ryser [2002]), separately per species, as

$$
a_{\mathrm{pop}}=\left[\frac{10^{a} \times 100}{\frac{A_{\text {pop }}}{10000}}\right]-\left[\frac{A_{\text {pop }}}{100}\left(\mathrm{Ol}_{\text {intra }}\right)\right] .
$$

The first term in brackets gives the minimum requirements for WD for a population of 100 individuals/ha. The individual requirements for WD in $\mathrm{m}^{2}\left(10^{a}=\right.$ backtransformed intercept from Fig. 2) were multiplied by 100 and divided by the total area covered by the home ranges of 100 individuals/ha $\left(A_{\mathrm{pop}} / 10000\right)$. The second term in parentheses reduces the population requirements for WD by the percentage of intraspecific home range overlap $\left(\mathrm{Ol}_{\text {intra }}\right)$. If there is no evidence for home range overlap, the second term in parentheses is zero. Bias in home range overlap estimates depends on the number of individuals tracked. Here, bias in home range overlap estimates seems rather small as late in the season most animals had radio transmitters (Indermaur et al. 2009a). We obtained confidence intervals for $a_{\text {pop }}$ by averaging the total home range area of 1000 bootstrapped samples of 100 randomly selected individuals.

\section{Results}

What is the amount of wood deposits that a single individual needs?-Home range size of both species strongly decreased with increasing area of WD (Fig. 3 ). For both species, significant evidence was found that animals adjust home range size to include a minimum amount of WD. The bootstrapped $95 \%$ confidence intervals $(\mathrm{CI})$ included -1 (B. b. spinosus, $y=1.68-$ $0.65 x$, CI for slope $[-1.08,-0.26]$, CI for intercept [1.13, 2.09], $R^{2}=0.28 ; B$. viridis, $y=1.83-0.84 x$, CI for slope $[-1.15,-0.57]$, CI for intercept $\left.[1.39,2.18], R^{2}=0.36\right)$. The individual minimum area requirements for WD were larger for $B$. viridis (mean $\pm \mathrm{SE}, 67.1 \pm 1.57 \mathrm{~m}^{2}$ ) than for B. b. spinosus $\left(47.8 \pm 1.65 \mathrm{~m}^{2}\right.$; Table 1, Fig. 3). For other habitat types no evidence for habitat dependence was found (see Appendix).

Which size of wood deposits is used over-proportionally compared to availability? - Bufo b. spinosus did not
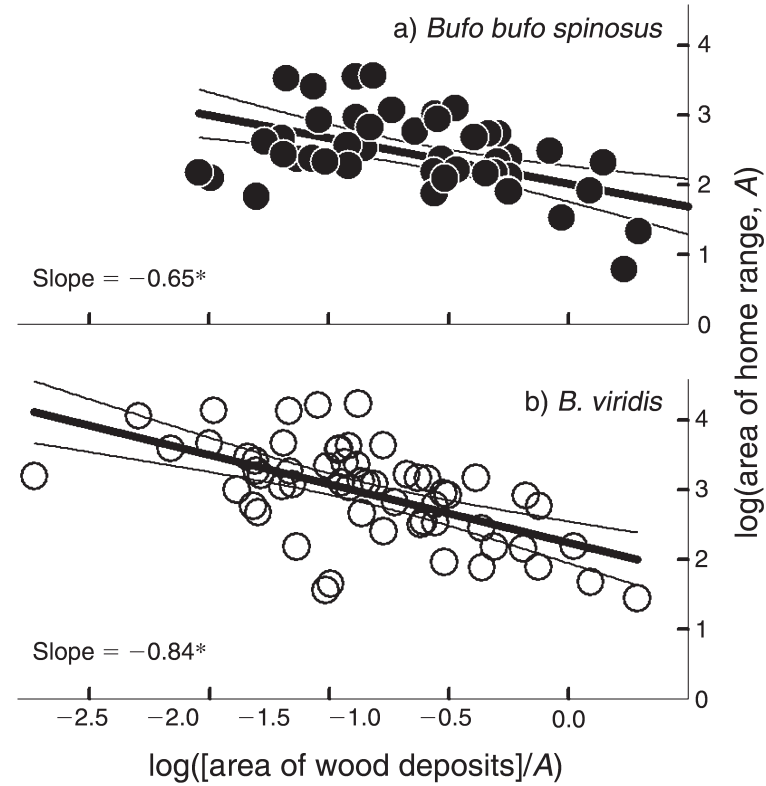

FIG. 3. Habitat-dependence analysis to determine minimum habitat requirements, based on pooled data of 2005 and 2006 . The log of the proportion of the area of wood deposits over home range area $(A)$ is regressed on the log of the home range area. The intercept gives the $\log$ of the minimum area requirements of wood deposits. Values are regression slopes. Regression slopes that are close to -1 suggest that animals increase $A$ to include a minimum amount of wood deposits within their home ranges. Asterisks indicate slopes that do not differ from -1 , i.e., bootstrap intervals include -1 .

discriminate between different sizes of WD $\left(\chi^{2}=2.866\right.$ $\mathrm{df}=4, P<0.580)$ while $B$. viridis $\operatorname{did}\left(\chi^{2}=17.447, \mathrm{df}=\right.$ $4, P=0.002$; Table 2$)$. However, $B$. viridis used only WD of smallest size $\left(<5 \mathrm{~m}^{2}\right)$ over-proportionally $\left(\chi^{2}=\right.$ 15.692, df $=1, P<0.001)$.

What is the amount of wood deposits that a population needs?-For both species, the total area covered by the home ranges of 100 individuals $\left(A_{\mathrm{pop}}\right)$ was high, and did not considerably change when corrected for both intraand interspecific home range overlap (home range area not corrected for overlap: B. b. spinosus: $59753 \mathrm{~m}^{2} ;$ B. viridis: $247807 \mathrm{~m}^{2}$; corrected for home range overlap: B. b. spinosus: $56514 \mathrm{~m}^{2}$; B. viridis: $213337 \mathrm{~m}^{2}$; Table 1). The minimum area requirements for WD for a population of 100 individuals per hectare were almost three times higher for $B$. b. spinosus, than for B. viridis (Table 1). The minimum requirements for WD for a population of 100 individuals can be easily recalculated for a population of any size based on Table 1. For example, as 100 individuals of $B$. b. spinosus require $756.9 \mathrm{~m}^{2} \mathrm{WD} / \mathrm{ha}, 50$ individuals would require 378.45 $\mathrm{m}^{2} \mathrm{WD} / \mathrm{ha}$.

\section{DisCUSSION}

We demonstrated how data on habitat selection behavior can be used to derive simple recommendations that can be communicated to conservation managers. 
TABLE 1. Individual-level and population-level requirements of a habitat type $(a)$, here wood deposits (WD).

\begin{tabular}{|c|c|c|c|c|c|c|c|}
\hline Code & Description & \multicolumn{3}{|c|}{ Bufo bufo spinosus } & \multicolumn{3}{|c|}{ B. viridis } \\
\hline$A_{\text {pop }}$ & total area covered by the home ranges of 100 individuals $\left(\mathrm{m}^{2}\right) \dagger$ & 59753 & 42599 & 77452 & 247807 & 179469 & 326938 \\
\hline$a_{\text {pop }}$ & requirements for WD for 100 individuals per hectare $\left(\mathrm{m}^{2} / \mathrm{ha}\right) \ddagger$ & 756.9 & 214.5 & 1983.5 & 233.2 & 85.5 & 534.4 \\
\hline
\end{tabular}

Notes: Key to abbreviations: LCL, lower 95\% confidence limit; UCL, upper $95 \%$ confidence limit (values are based on 1000 bootstrap samples of 100 randomly selected individuals, separately for $B$. b. spinosus and B. viridis); $a_{\text {ind }}$ is the back-transformed intercept $\left(10^{\text {intercept }}\right)$ from Fig. $2, a_{\text {pop }}=\left(a_{\text {ind }} \times\right.$ number of 100 individuals $) /\left(A_{\text {pop }}\right.$ per hectare $)-($ percentage of intraspecific home range overlap). Multiplication of $a_{\text {ind }}$ and $A_{\text {pop }}$ by factor 10 would transform $\mathrm{m}^{2}$ and $\mathrm{m}^{2} /$ ha into $\mathrm{m}^{3}$ and $\mathrm{m}^{3} / \mathrm{ha}$, respectively. This factor was derived from Bütler and Schlaepfer (2004).

$\dagger$ Not corrected for home range overlap.

t Corrected for home range overlap.

Our key results are that (1) amphibian populations have great demands for WD and space and we quantify the amount of WD required by individuals and populations and (2) species differ in the amount of WD and one species significantly prefers WD of smallest size. We use these key results to quantify habitat requirements in a way that can be used directly by conservationists. Even though our previous research showed that WD is the key resource (Indermaur et al. 2009a, $b$ ), there may be other resources that may affect individual and populationlevel habitat requirements.

Both species of toads used WD over-proportionally, suggesting WD to be a key elements for thermoregulation and predator avoidance in terrestrial summer habitats (see Indermaur et al. 2009a, $b$ ). The estimated amount of WD required per individual was large: $47 \mathrm{~m}^{2}$ for B. b. spinosus and $67 \mathrm{~m}^{2}$ for B. viridis (Table 1). For a population of 100 toads, $756 \mathrm{~m}^{2}$ and $233 \mathrm{~m}^{2} \mathrm{WD} / \mathrm{ha}$ were necessary (Table 1). Even though conservation managers often manage habitats in such a way that WD is available for amphibians, the estimated amounts of WD are much more than is currently available in amphibian habitats (B. R. Schmidt, personal observa- tion). However, the amount of WD can be easily increased by conservation managers; the best solution would be to allow or restore natural processes that lead to WD, e.g., natural flow regimes and riparian forests. It would be worthwhile to estimate density or abundance of animals before and after addition of WD to confirm success of the management action (as Stewart and Pough [1983] did). While the focus of our study is on toads, we believe that adding WD to improve the quality of terrestrial habitat for amphibians would certainly also benefit other animals and fungi (Bütler et al. 2004, Bunnell and Houde 2010).

We used habitat-dependence analysis (Kenward 2001) to find that toads adjust home range size to include a minimum amount of WD. In other words home ranges shrink when habitat quality, expressed by WD, increases. This piece of information can be used by conservationists. Adding WD to amphibian terrestrial habitat increases the carrying capacity such that a larger population can live in a given area. Stewart and Pough (1983) demonstrated experimentally that addition of refuges leads to an increase in population size. However, WD cannot be added indefinitely. We would not

TABLE 2. Distribution of available and used wood deposits across five size classes, separately per species with $\chi^{2}$ statistics.

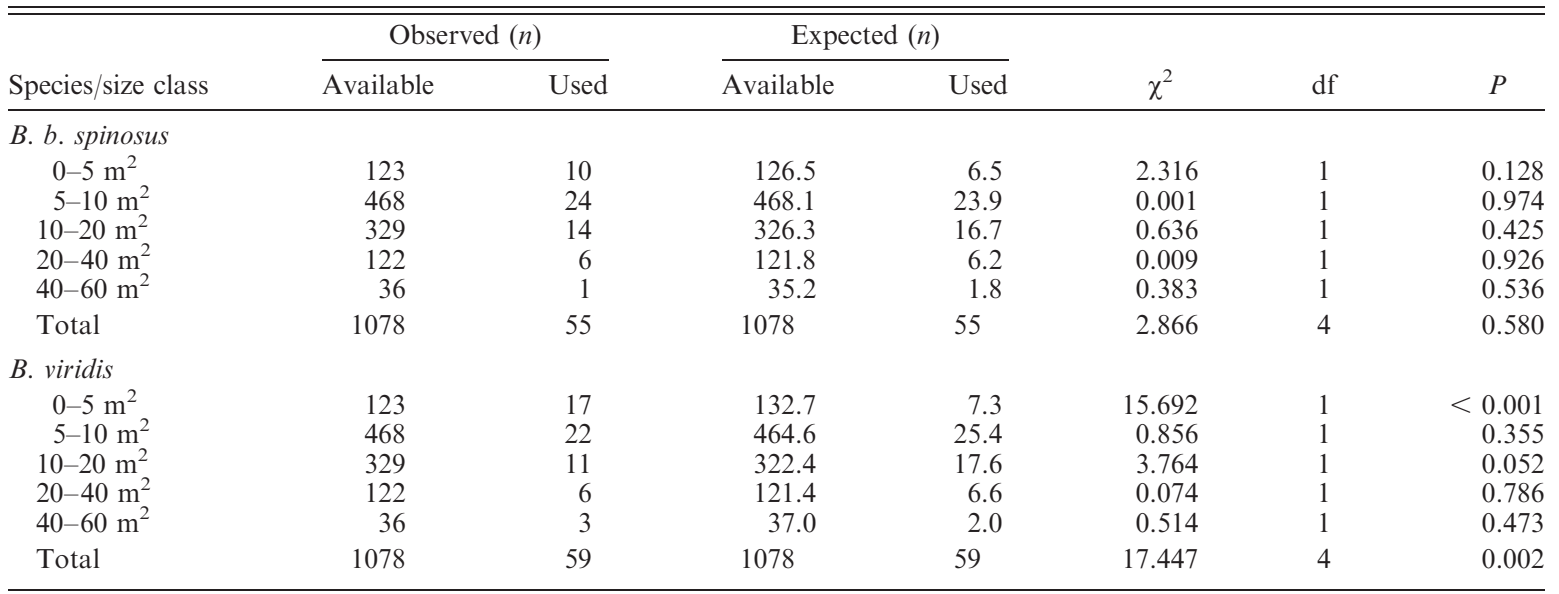

Notes: Whether use differed from availability was tested overall size classes, which refers to a $5 \times 2$ table $\left(\chi^{2}\right.$ statistics in the rows with totals $)$ and separately per size class $(2 \times 2$ table $)$. In the latter case, the numbers within a size class were tested against the sums in remaining size classes. The overall test was significant for B. viridis but not for B. b. spinosus. Bufo viridis used only wood deposits $<5 \mathrm{~m}^{2}$ over-proportionally. 
recommend going much beyond the estimates reported in Table 1. Moreover, whether improvement in habitat quality translates to higher population density will likely depend on the relative importance of density dependent and density independent processes. While there is evidence for density dependence in the terrestrial stage (Altwegg 2003, Harper et al. 2008), others have argued that adult densities are largely determined by stochastic, density-independent processes (Beebee et al. 1996). Generality also requires that species-habitat associations do not vary geographically (Whittingham et al. 2007). Such variation may indeed occur in the common toad (Zanini et al. 2009). Yet, because WD is a multifunctional resource (shelter and food) we think that it is important for the two species in general. Nevertheless, geographic variation may lead to some spatial variation in the minimum amounts of WD.

WD comes in different sizes which were partly differentially used by one of the two species studied (Table 2). Even though preference for small WD in $B$. viridis was not very strong, managers should make sure that small WD are available. The estimated minimum area for a population of 100 individuals of $B . b$. spinosus was within the range of earlier but less rigorous estimates (Ryser 2002, Schmidt 2008b). The estimate for $B$. viridis was much larger, however. Such large areas are not always available. For example, in Switzerland the areas of amphibian breeding sites of federal importance are generally much smaller than the area requirements reported in table 2 (Borgula et al. 1994). This implies that amphibian breeding sites of federal importance alone cannot guarantee the persistence of amphibian populations. Therefore, the matrix surrounding the core habitat must be suitable for amphibians as well (Petranka and Smith 2005).

\section{Conclusion}

We have shown how analysis of data on individual behavior can make a contribution to conservation practice. Previously, we showed that WD is most important for toads. By applying habitat-dependence analysis we derived quantitative estimates of how much WD a single toad and a population requires. Our results suggest that various sizes of WD would support multiple species. Additionally, we quantified the area requirements of a population. These areas are much larger than what is often available for animal populations.

Recommendations in many articles published in conservation journals are often vague (Arlettaz et al. 2010). Vague recommendations are not useful when conservation managers must make decisions. Vagueness of recommendations is certainly one of the reasons why conservation science is rarely used by conservation practitioners. We expressed our results in simple numbers that can easily be communicated to conservation managers (e.g., Schmidt and Zumbach 2010). We believe that conservation biology will become a more useful endeavor if more conservation scientists use their results to derive simple rules of thumb for conservation managers. This effort would certainly help to reduce the gap between conservation science and practice.

\section{ACKnowledgments}

We are grateful to M. Gehring, T. Winzeler, and W. Wehrle for help with data collection. We thank M. Schaub and G. Pasinelli for their comments, which improved the manuscript. The project was funded by the MAVA Foundation (Switzerland). All methods applied conform to the ethical and animal care guidelines issued by national (Ministerio dell'Ambiente e della Tutela del Territorio, Direzione per la Protezione della Natura, Roma) and the regional (Direzione Centrale Risorse Agricole, Forestali e Naturali, Regione Friuli Venezia Giulia, Udine) authorities in Italy who kindly provided permits.

\section{Literature Cited}

Altwegg, R. 2003. Multistage density dependence in an amphibian. Oecologia 136:46-50.

Arlettaz, R., M. Schaub, J. Fournier, T. S. Reichlin, A. Sierro, J. E. M. Watson, and V. Braunisch. 2010. From publications to public actions: when conservation biologists bridge the gap between research and action. BioScience 60:835-842.

Beebee, T. J. C., J. S. Denton, and J. Buckley. 1996. Factors affecting population densities of adult natterjack toads Bufo calamita in Britain. Journal of Applied Ecology 33:263-268.

Biek, R., W. C. Funk, B. A. Maxell, and L. S. Mills. 2002. What is missing in amphibian decline research: insights from ecological sensitivity analysis. Conservation Biology 16:728734

Borgula, A., P. Fallot, and J. Ryser. 1994. Inventar der Amphibienlaichgebiete von nationaler Bedeutung-Schlussbericht. Schriftenreihe Umwelt Nr. 233. Bundesamt für Umwelt, Wald und Landschaft, Bern, Switzerland.

Buchholz, R. 2007. Behavioural biology: an effective and relevant conservation tool. Trends in Ecology and Evolution 22:401-407.

Bunnell, F. L., and I. Houde. 2010. Down wood and biodiversity - implications to forest practices. Environmental Reviews 18:397-421.

Bütler, R., P. Angelstam, P. Ekelund, and R. Schlaepfer. 2004 Dead wood threshold values for the three-toed woodpecker presence in boreal and sub-Alpine forest. Biological Conservation 119:305-318.

Bütler, R., and R. Schlaepfer. 2004. Wieviel Toholz braucht der Wald? Schweizerische Zeitschrift für Forstwesen 155:31-37.

Caro, T. 2007. Behavior and conservation: a bridge too far? Trends in Ecology and Evolution 22:394-400.

Carrier, J. A., and T. J. C. Beebee. 2003. Recent, substantial, and unexplained declines of the common toad Bufo bufo in lowland England. Biological Conservation 111:395-399.

Crawford, J. A., and R. D. Semlitsch. 2007. Estimation of core terrestrial habitat for stream-breeding salamanders and delineation of riparian buffers for protection of biodiversity. Conservation Biology 21:152-158.

Fazey, I., J. Fischer, and D. B. Lindenmayer. 2005. What do conservation biologists publish? Biological Conservation 124:63-73.

Ferguson, S. H., M. K. Taylor, E. W. Born, A. Rosing-Asvid, and F. Messier. 1999. Determinants of home range size for polar bears (Ursus maritimus). Ecology Letters 2:311-318.

Ficetola, G. F., E. Padoa-Schioppa, and F. De Bernardi. 2009 Influence of landscape elements in riparian buffers on the conservation of semiaquatic amphibians. Conservation Biology 23:114-123.

Halley, J. M., R. S. Oldham, and J. W. Arntzen. 1996. Predicting the persistence of amphibian populations with the help of a spatial model. Journal of Applied Ecology 33:455470 . 
Harper, E. B., T. A. G. Rittenhouse, and R. D. Semlitsch. 2008. Demographic consequences of terrestrial habitat loss for pool-breeding amphibians: predicting extinction risks associated with inadequate size of buffer zones. Conservation Biology 22:1205-1215.

Indermaur, L., M. Gehring, W. Wehrle, K. Tockner, and B. Naef-Daenzer. 2009a. Behavior-based scale definitions for determining individual space use: requirements of two amphibians. American Naturalist 173:60-71.

Indermaur, L., T. Winzeler, B. R. Schmidt, K. Tockner, and M. Schaub. 2009b. Differential resource selection within shared habitat types across spatial scales in sympatric toads. Ecology 90:3430-3444.

Kenward, R. E. 2001. A manual for wildlife radio tagging. Academic Press, San Diego, California, USA.

MacDonald, D. W. 1983. The ecology of carnivore social behaviour. Nature 301:379-384.

Moore, J., B. Bell, and W. Linklater. 2008. The debate on behavior in conservation: New Zealand integrates theory with practice. BioScience 58:454-459.

Petranka, J. W., and C. K. Smith. 2005. A functional analysis of streamside habitat use by southern Appalachian salamanders: implications for riparian forest management. Forest Ecology and Management 210:443-454.

Petts, G. E., A. M. Gurnell, A. J. Gerrard, D. M. Hannah, B. Hansford, I. Morrissey, P. J. Edwards, J. Kollmann, J. V. Ward, K. Tockner, and B. P. G. Smith. 2000. Longitudinal variations in exposed riverine sediments: a context for the ecology of the Fiume Tagliamento, Italy. Aquatic Conservation 10:249-266.

Pullin, A. S., and T. M. Knight. 2005. Assessing conservation management's evidence base: a survey of management-plan compilers in the United Kingdom and Australia. Conservation Biology 19:1989-1996.

R Development Core Team. 2009. R: a language and environment for statistical computing. R Project for Statistical Computing, Vienna, Austria. 〈http://www.R-project. org $>$

Ryser, J. 2002. Bundesinventar der Amphibienlaichgebiete von nationaler Bedeutung - Vollzugshilfe. Bundesamt für Umwelt, Wald und Landschaft, Bern, Switzerland.

Schmidt, B. R. 2008a. Steps towards better amphibian conservation. Animal Conservation 11:469-471.

Schmidt, B. R. 2008b. Umsiedlung einer Amphibienpopulation in der Schweiz. Pages 112-113 in P. Dollinger, editor. Amphibien brauchen unsere Hilfe-Verhandlungsbericht des Amphibienkurses in Chemnitz, 27.-30. Juni 2007. World Association of Zoos and Aquariums, Bern, Switzerland.
Schmidt, B. R., R. Feldmann, and M. Schaub. 2005. Demographic processes underlying population growth and decline in Salamandra salamandra. Conservation Biology 19:1149-1156.

Schmidt, B. R., and S. Zumbach. 2005. Rote Liste der gefährdeten Amphibien der Schweiz. BUWAL-Reihe. Vollzug Umwelt, Bundesamt für Umwelt, Wald und Landschaft, Bern, Switzerland.

Schmidt, B. R., and S. Zumbach. 2010. Neue Herausforderungen und Wege im Amphibienschutz. Wildbiologie 4/37:116.

Semlitsch, R. D. 1998. Biological delineation of terrestrial buffer zones for pond-breeding salamanders. Conservation Biology 12:1113-1119.

Semlitsch, R. D. 2003. Conservation of pond-breeding amphibians. Pages 8-23 in R. D. Semlitsch, editor. Amphibian conservation. Smithsonian Institution, Washington, D.C., USA.

Semlitsch, R. D., and J. R. Bodie. 2003. Biological criteria for buffer zones around wetlands and riparian habitats for amphibians and reptiles. Conservation Biology 17:12191228

Sindaco, R., G. Doria, E. Razzetti, and F. Bernini, editors. 2006. Atlante degli anfibi e dei rettili d'Italia/atlas of Italian amphibians and reptiles. Edizione Polistampa, Firenze, Italy.

Stewart, M. M., and F. H. Pough. 1983. Population density of tropical forest frogs: relation to retreat sites. Science 222:570-572.

Stuart, S. N., J. S. Chanson, N. A. Cox, B. E. Young, A. S. L. Rodrigues, D. L. Fischman, and R. W. Waller. 2004. Status and trends of amphibian declines and extinctions worldwide. Science 306:1783-1786.

Sutherland, W. J. 1998. The importance of behavioural studies in conservation biology. Animal Behaviour 56:801-809.

Sutherland, W. J., A. S. Pullin, P. M. Dolman, and T. M. Knight. 2004. The need for evidence-based conservation. Trends in Ecology and Evolution 19:305-308.

Trenham, P. C., and H. B. Shaffer. 2005. Amphibian upland habitat use and its consequences for population viability. Ecological Applications 15:1158-1168.

Whittingham, M. J., J. R. Krebs, R. D. Swetnam, J. A. Vickery, J. D. Wilson, and R. P. Freckleton. 2007. Should conservation strategies consider spatial generality? Farmland birds show regional not national patterns of habitat association. Ecology Letters 10:25-35.

Zanini, F., J. Pellet, and B. R. Schmidt. 2009. The transferability of distribution models across regions: an amphibian case study. Diversity and Distributions 15:469-480.

\section{APPENDIX}

Results of habitat-dependence analyses to determine minimum habitat requirements for four habitat types (Ecological Archives A021-114-A1). 